\title{
Aquilaria malaccensis Leaf as an Alternative Source of Anti- inflammatory Compounds
}

\author{
Manar Eissa ${ }^{1}$, Yumi Z. H-Y. Hashim¹, Nur Aimi A. Zainurin ${ }^{2}$ \\ ${ }^{1}$ International Institute for Halal Research and Training (INHART), International Islamic University Malaysia (IIUM), Jalan \\ Gombak, 53100 Kuala Lumpur, Malaysia \\ E-mail: manareissa1210@gmail.com; yumi@iium.edu.my
}

${ }^{2}$ Department of Biotechnology Engineering, Kulliyyah of Engineering, International Islamic University Malaysia (IIUM), Jalan Gombak, 53100 Kuala Lumpur, Malaysia

E-mail: aimialiahz@yahoo.com

\begin{abstract}
Currently, the long-term consumption of aspirin and non-aspirin non-steroidal anti-inflammatory drugs (NSAIDs) as antiinflammatory medicines and pain relievers, have been reported to cause various side effects. Thus, natural compounds of several plant species including Aquilaria malaccensis have been explored as an alternative therapeutic source for inflammation treatment with regard to their safety and efficacy. Despite the accelerating rate on the research of agarwood leaf, the scientific evidences to elucidate the proclaimed pharmacological activities particularly anti-inflammatory activity are still limited. Therefore, it is the interest of this study to investigate the biological activity relating to the anti-inflammatory activity of $\boldsymbol{A}$. malaccensis leaf extracted using Soxhlet and Supercritical Fluid Extraction (SFE) methods. Results showed that A. malaccensis leaf ethanolic soxhlet extract (ALEXB) gave higher yield $(\mathrm{mg} / \mathrm{g})$ of $98.33 \pm 4.11(9.83 \% \mathrm{wt} / \mathrm{wt})$ as compared to soxhlet extract using hexane (ALEXA); $24.04 \pm 5.27$ $(2.40 \% \mathrm{wt} / \mathrm{wt})$ after 6 hours of extraction. Meanwhile, the supercritical fluid extract (SFEX) gave a relatively low yield of $12.57 \pm 0.61$ $(1.26 \% \mathrm{wt} / \mathrm{wt})$. The GCMS analysis revealed that 25,30 and 16 compounds were detected in ALEXA, ALEXB and SFEX respectively with phytol as the major compound in the soxhlet extracts and n-hexadecanoic as a major compound in SFEX. Subsequently, in-vitro study showed that the extracts demonstrated inhibition of protein (albumin) denaturation in a concentration-dependent manner throughout a concentration range of $400-16000 \mu \mathrm{g} / \mathrm{ml}$ tested. Exclusively, the GCMS of leaf SFEX showed a peak of $1 \mathrm{H}$ Cycloprop[e]azulene, decahydro-1,1,7-trimethyl-4-methylene $(0.4205 \%)$, a tricyclic sesquiterpene that was testified to have potential analgesic and anti-inflammatory activity. Further research is warranted to explore the anti-inflammatory activities of $A$. malaccensis leaf extracts and their mechanism of action as an alternative halal ingredient for nutraceuticals and pharmaceuticals.
\end{abstract}

Keywords — anti-inflammatory; Aquilaria malaccensis; halal; SFE; Soxhlet

\section{INTRODUCTION}

Inflammation is a complex biological response of the immune system to tissue damage or infection. Although inflammation is a crucial element in maintaining normal body's homeostasis, it plays pivotal role in a number of chronic devastating diseases, including cancer, diabetes, arthritis and cardiovascular diseases [1].

Currently, the long-term consumption of aspirin and nonaspirin non-steroidal anti-inflammatory drugs (NSAIDs) as anti-inflammatory medicines and pain relievers, have been reported to cause various side effects such as kidney toxicity, haemorrhagic stroke, gastrointestinal ulceration and bleeding [2], [3]. Thus, natural compounds of various plant species have been explored as an alternative and halal therapeutic source for inflammation related conditions [4], [5]. Being halal is not only confined to the Islamic concept which means the product is free from any ingredients that is prohibited in Islam, but it is a novel benchmark for safety and quality assurance to ascertain the product is safe, pure and harmless [6], [7].

Plenty of plant extracts have been recognized to demonstrate anti-inflammatory activity, and therefore traditionally used for treatment of inflammation in topical and oral preparations. Several parts of Aquilaria species have also been reported to exhibit anti-inflammatory effect in a number of recently published articles [8]-[11].

Agarwood species have been utilized for myriad types of applications mainly as folk medicine, perfume and incense. Agarwood has also been counted as an Ayurvedic, 
traditional Chinese medicine as well as traditional Thai medicine [12]. In particular, Aquilaria malaccensis is one of the Aquilaria species that belongs taxonomically to family Thymelaeaceae. This genus is mainly distributed in Malaysian rainforests. A.malaccensis is the main producer of the resin-impregnated fragrant wood (known as agarwood) formed in the trunk of the tree following injuries or infection [13].

Agarwood plant has been mentioned in Appendix II of the Convention on International Trade in Endangered Species of Wild Fauna and Flora and protected as an endangered species (CITES) following the dwindling number of the wild trees due to irrational cutting to obtain its aromatic resin [14], [15]. In response to the scenario, there is now an increasing number of agarwood plantation that is managed more systemically; with abundant and continuous supply of leaf as source of raw material.

Agarwood leaf generally has a length of 5 to $11 \mathrm{~cm}$ and diameter of 2 to $4 \mathrm{~cm}$ with an elliptical blades shape [16]. A wide range of functional groups with diverse potential bioactive compounds has been identified in agarwood leaf [17]. It is reported that the agarwood leaf extract possesses various pharmacological effects including anticancer, antiallergic, antiviral as well as anti-inflammatory [17], [18]. In Malaysia, the decoction of $A$. malaccensis leaf has been reported to be applied externally to treat swelling and consumed to treat vomiting [19]. Meanwhile, the medicinal health effects of agarwood tea (the most popular agarwood leaf-based product in the market) have been recorded for many years. Ibrahim (2016) stated that, the herbal tea of $A$. malaccensis, A. crassna and A. sinensis were found to have antidepressant and anti-aging properties [19].

Despite the accelerating rate on the research of agarwood leaf, the scientific evidences to elucidate the proclaimed pharmacological activities are still limited. Pharmacological actions of crude extracts from various parts of Aquilaria species summarized by Hashim et al. (2016) showed that anti-inflammatory activities were observed in the ethanolic and methanolic leaf extract of $A$. sinensis (Lour) Gilg. and $A$. crassna respectively [17]. However, to the best of our knowledge, the anti-inflammatory activity from $A$. malaccensis leaf has not been reported. Therefore, it is the interest of the current study to explore the anti-inflammatory activity of A. malaccensis leaf extracted using Soxhlet method and Supercritical Fluid Extraction (SFE), intending to reveal the evidence for its folkloric uses as well to initiate further exploitation of halal, safe and effective abundant resources of $A$. malaccensis leaf.

\section{THE MATERIAL AND METHOD}

\section{A. Plant Material}

Fresh leaves of non-inoculated A. malaccensis (agarwood plant which was not being induced or injected with microbial concoction for development of resin) were freshly harvested from local agarwood farm in Bangi, Selangor, Malaysia in February 2018. The leaves were oven-dried at a temperature of $40^{\circ} \mathrm{C}$ overnight. The sample was then ground to a size of $\leq 200 \mu \mathrm{m}$. The powder was kept in the dark in sealed glass bottles at room temperature.

\section{B. Chemicals}

Analytical grade reagents and solvents used in this experiment were obtained from Sigma-Aldrich Chemicals (St. Louis, MO, USA) and Merck Chemicals (Darmstadt, FR Germany) unless otherwise stated.

\section{Extraction}

1) Soxhlet extraction: Soxhlet extraction method was performed using $300 \mathrm{ml}$ of hexane and ethanol as the solvent respectively. An amount of 6 grams of the powder was placed in the thimble in the Soxhlet chamber. The extraction was run for 6 hours. Change of colour of solvent in the thimble into its original state indicated that all bioactive compounds have been extracted. The extract was evaporated under reduced pressure at $40^{\circ} \mathrm{C}$ using a rotary evaporator (Heidolph-instruments, Rotavapor, Germany) to obtain concentrated hexane and ethanolic extracts. The weight of the crude extracts were measured after evaporation of excess solvent and preserved in a petri dish sealed with aluminium foil for further analysis [20]-[21].

2) Supercritical fluid extraction: Supercritical fluid extraction was performed in the SFE unit (Supercritical Fluid Centre, Faculty of Food Science and Technology, Universiti Putra Malaysia). The process was done for two batches. The extractor vessel was loaded with $480.5 \mathrm{~g}$ (batch 1) and $420 \mathrm{~g}$ (batch 2) of dried and ground A. malaccensis leaves with particle size $\leq 200 \mu \mathrm{m}$. Liquid carbon dioxide flow into the extractor vessel at a flow rate $6-7 \mathrm{~kg} / \mathrm{hr}$ at a temperature of $50^{\circ} \mathrm{C}$ and pressure adjusted to 350 bar. The extract was separated at the separator vessel once carbon dioxide changes to gaseous state upon reducing the pressure.

The yields obtained from the two extraction methods were calculated by using the following equation (1) [20]:

$$
y=\mathrm{W}_{2} / \mathrm{W}_{1}
$$

Where $\quad y$ : yield of extract $(\mathrm{mg} / \mathrm{g})$

$\mathrm{W}_{1}$ : weight of sample $(\mathrm{g})$

$\mathrm{W}_{2}$ : weight of agarwood leaf extract $(\mathrm{mg})$

\section{Gas chromatography-mass spectrometry (GCMS) analysis of A.malaccensis leaf extracts}

1) Sample preparation: A.malaccensis leaf soxhlet extracts were diluted in respective solvent and supercritical fluid extract was dissolved in hexane to obtain $1 \%(\mathrm{w} / \mathrm{v})$ extract, respectively. $10 \mu \mathrm{l}$ of the prepared extract was mixed with $990 \mu \mathrm{l}$ of the respective solvents into $1 \mathrm{ml}$ microcentrifuge tube and stirred well. After filtration, the mixture transferred into vials for GCMS analysis. All samples were prepared in triplicates [22].

2) GCMS analysis: The volatile constituents of the triplicate A.malaccensis leaf extract samples were analysed by using gas chromatography system; Agilent 7890A (Agilent Technologies) coupled with Agilent 5975C quadrupole mass spectrometer and autosampler. Hewlett Packard HP-5MS ultra inert silica capillary column (30 m x $0.25 \mathrm{~mm} ; 0.25 \mu \mathrm{m}$ ) was used. The analytical conditions for GCMS are listed in Table 1. The detected peaks from the total ion chromatography (TIC) and mass chromatograms 
were identified based on National Institute of Standards and Technology (NIST) 2008 mass spectral library [23].

TABLE 1.

ANALYTICAL CONDITIONS FOR GCMS ANALYSIS BASED ON HASHIM ET AL [23].

\begin{tabular}{|c|c|c|c|c|c|}
\hline \multicolumn{4}{|c|}{\begin{tabular}{|l|l|}
2 \\
\end{tabular}} & \multicolumn{2}{|c|}{ Conditions } \\
\hline \multicolumn{4}{|c|}{ Carrier gas } & \multicolumn{2}{|c|}{$\mathrm{He}$} \\
\hline \multicolumn{4}{|c|}{ Gas flow } & \multicolumn{2}{|l|}{$2 \mathrm{ml} / \mathrm{min}$} \\
\hline \multicolumn{4}{|c|}{ Split Ratio } & \multicolumn{2}{|l|}{$1: 50$} \\
\hline \multicolumn{4}{|c|}{ Injection Volume } & \multicolumn{2}{|l|}{$1 \mu \mathrm{l}$} \\
\hline \multicolumn{4}{|c|}{ Mode } & \multicolumn{2}{|l|}{ Split } \\
\hline \multicolumn{4}{|c|}{ Interface temperature } & \multicolumn{2}{|l|}{$250^{\circ} \mathrm{C}$} \\
\hline \multicolumn{4}{|c|}{ Electron impact (emission current) } & \multicolumn{2}{|l|}{$70 \mathrm{eV}$} \\
\hline \multicolumn{4}{|c|}{ Scan range } & \multicolumn{2}{|c|}{32 to $500 \mathrm{amu}$} \\
\hline \multirow{3}{*}{$\begin{array}{l}\text { Oven } \\
\text { Program }\end{array}$} & & $\begin{array}{l}\text { Rate } \\
\left({ }^{\circ} \mathrm{C} / \mathrm{min}\right)\end{array}$ & $\begin{array}{l}\text { Value } \\
\left({ }^{\circ} \mathrm{C}\right)\end{array}$ & $\begin{array}{l}\text { Hold time } \\
\text { (Min) }\end{array}$ & $\begin{array}{l}\text { Run } \\
\text { time } \\
\text { (Min) }\end{array}$ \\
\hline & Initial & - & 80 & 2 & 2 \\
\hline & Ramp & 10 & 250 & 10 & 29 \\
\hline
\end{tabular}

\section{E. In-vitro anti-inflammatory assay}

The assay was conducted following the procedure in [5] with some modification. The reaction mixture consisted of 2 $\mathrm{ml}$ of varying concentrations of the test extract $(400,800$, $2000,4000,8000$ and $16000(\mu \mathrm{g} / \mathrm{ml}), 0.2 \mathrm{ml}$ of egg albumin and $2.8 \mathrm{ml}$ phosphate buffer saline $(\mathrm{pH} \mathrm{6.4)}$. Equal volume of deionized water served as control. The mixtures were incubated for $15 \mathrm{~min}$ at $37^{\circ} \mathrm{C} \pm 2{ }^{\circ} \mathrm{C}$ in a biological oxygen demand incubator and heated afterwards for $5 \mathrm{~min}$ at $70^{\circ} \mathrm{C}$. After cooling, the absorbance of the test and control solutions was measured at $\lambda=660 \mathrm{~nm}$. The assay was done in triplicates. The percentage of inhibition of protein denaturation was calculated by using the following equation (2) $[5]$ :

$$
\text { \% Inhibition }=100 \times\left[\left(\frac{V t}{V c}\right)-1\right]
$$

Where Vt: absorbance of test sample Vc: absorbance of control

\section{RESULT AND DISCUSSION}

\section{A. Yield of Aquilaria malaccensis leaf extracts}

Results presented in Table 2 and Table 3 showed that Soxhlet (ALEX) extraction method with ethanol (B) as solvent gave the higher yield $(\mathrm{mg} / \mathrm{g})$ of $98.330 \pm 4.113$ (9.83\% wt/wt) as compared to ALEX with hexane (A) as solvent $24.039 \pm 5.268(2.40 \% \mathrm{wt} / \mathrm{wt})$ after 6 hours of extraction, and (SFEX) obtained by SFE extraction $12.57 \pm$ 0.608 (1.25\% wt/wt). Similarly, Hendra et al. (2016) reported that the A. malaccensis leaf extracted using Soxhlet with different types of solvents had the yield percentage of methanol (9.2\%), chloroform (3.4\%) and water (1.9\%) [24]. Bimakr et al. (2011) revealed that the yield percentage of spearmint (Mentha spicata L.) leaf extracted using Soxhlet for 6 hours, 3 grams of sample and $150 \mathrm{ml}$ of methanol and ethanol as solvent were $8.91 \%$ and $7.27 \%$ respectively [25]. Meanwhile, a former study conducted by Muruganandam et al. (2017) discovered that the optimum yield of Piper betle leaf ethanolic Soxhlet extract was $10.94 \%$ with optimum extraction time of 3 hours, temperature of $71.91^{\circ} \mathrm{C}$, solvent volume of $281.43 \mathrm{ml}$ and sample weight of 2 grams [26].
The yield obtained in this present study is comparable with the previous studies. Studies showed that the yield of extract is highly influenced by the types of solvent regardless of the solvent volume, extraction time and sample weight. The present and previous studies have shown that the mid-polar solvent such as ethanol and methanol gave the highest yield as compared to non-polar and polar solvent. The higher yield of ALEXB as compared to ALEXA could be due to the existence of hydroxyl $(\mathrm{OH})$ group and ethyl $\left(\mathrm{C}_{2} \mathrm{H}_{5}\right)$ group in ethanol that enable the solvent to extract both polar and nonpolar compounds respectively [26]. Unlike hexane, the solvent can only dissolve nonpolar compounds [26]. Eventhough polar and non-polar solvents vary in their abilities and effeciencies in extracting the bioactive compounds, in terms of yield, it can be concluded that polar solvent promoted a higher yield of extract as compared to non-polar solvent [24].

In the current study, SFE yielded relatively small amount of Aquilaria malaccensis leaf extract compared to the conventional Soxhlet method using ethanol and hexane. The result is consistent with a similar study in literature that aimed to compare the yields of the Soxhlet and SFE methods of Nettle Root (Urtica dioica L.), and it was recognized that the highest yield percentage was attained by Soxhlet extraction with ethanol (14.14\%), followed by Soxhlet extraction by $n$-Hexane $(0.768 \%)$, while the supercritical extraction has a lower yield $(0.537 \%)$ [27]. Similarly, $70 \%$ ethanol soxhlet extraction showed a higher crude extract yield percentage $(8.58 \%)$ compared to the SFE extraction $(0.2 \%)$ in extracting spearmint (Mentha spicata L.) leaves [25]. The Extraction of Peanut Skin using ethanol soxhlet extraction a higher yield percentage $(36.282 \%)$ as compared with supercritical CO2 extraction (15.47\%) [28]. Despite its relatively low yield percentage, some studies testified that the extract obtained by SFE featured better quality and greater number of flavonoids [25], as well as higher phenolic content and enhanced radical scavenging activity [29] compared to Soxhlet extraction. SFE was likewise used in extracting Aquilaria species in a number of studies. A. malaccensis stem bark was ground to a particle size $\leq 500$ $\mu \mathrm{m}$ and extracted by $\mathrm{SFE}$ at $50^{\circ} \mathrm{C}$, under pressure of 34.5 $\mathrm{MPa}$; with $\mathrm{CO} 2$ flow rate $\leq 1 \mathrm{ml} / \mathrm{min}$, for $30 \mathrm{~min}$., and the yield obtained was as low as $3.66 \mathrm{~g}$ oil/100g sample [19]. It was also observed that the addition of a co-solvent to SFE process increased the yield obtained as reported in a study performed on the dried agarwood oil of Aquilaria crassna by Wetwitayaklung et al. (2009), which showed that the yield percentage without co-solvent $(0.06 \%)$ increased to $0.14 \%$ upon addition of ethanol co-solvent to the extraction process [30].

TABLE II

YIELD OF AQUILARIA MALACCENSIS LEAF CRUDE EXTRACT (ALEX) OBTAINED THROUGH SOXHLET; A: HEXANE, B: ETHANOL: VALUES ARE MEAN \pm SD.

\begin{tabular}{|l|l|l|}
\hline Sample & ALEXA & ALEXB \\
\hline Weight of sample/run (g) & $6.01 \pm 0.01$ & $6.01 \pm 0.00$ \\
\hline Weight of extract $(\mathbf{m g})$ & $144.30 \pm 31.53$ & $591.00 \pm 24.76$ \\
\hline Yield (mg/g) & $24.04 \pm 5.27$ & $98.33 \pm 4.11$ \\
\hline Yield \% (wt/wt) & $2.40 \pm 0.53$ & $9.83 \pm 0.41$ \\
\hline *wt: weight &
\end{tabular}


TABLE III

YIELD OF AQUILARIA MALACCENSIS LEAF CRUDE EXTRACT OBTAINED THROUGH SUPERCRITICAL FLUID EXTRACTION (SFE)

\begin{tabular}{|l|c|c|}
\hline \multirow{2}{*}{ Sample } & \multicolumn{2}{|c|}{ SFEX } \\
\cline { 2 - 3 } & Run 1 & Run 2 \\
\hline Weight of sample & 480.50 & 420.00 \\
\hline Weight of extract (mg) & 6250.00 & 5100.00 \\
\hline Yield (mg/g) & 13.00 & 12.14 \\
\hline Average yield & $12.57 \pm 0.61$ \\
\hline Yield \% (wt/wt) & 1.30 & 1.21 \\
\hline Average yield \% & $1.26 \pm 0.06$ \\
\hline
\end{tabular}

\section{B. GCMS analysis of Aquilaria malaccensis leaf extracts}

Methods of extraction may affect the chemical profile of the leaves. GCMS analysis revealed that the different types of extracts gave different number of peaks and compounds; ALEXA (26 peaks with 25 compounds), ALEXB (40 peaks with 30 compounds) while SFEX (16 peaks with 16 compounds). Phytol was the most abundant compound detected at retention time of 18.26 min which accounted for $34.062 \%$ and $29.267 \%$ respectively of all ALEXA and ALEXB contents, while Phytol was absent in the SFEX. On the other hand, n-hexadecanoic recorded the highest level $(38.93 \%)$ in SFEX. Due to the solvent power of $\mathrm{CO}_{2}$, SFE is proposed to dissolve non-polar hydrophobic compounds, while the extraction of polar hydrophilic components is challenging [31]. Accordingly, the absecnce of phytol (a polar diterpene alcohol) in SFEX is justifiable. However, Phytol was reported earlier in the chemical composition of Mentha spicata L. obtained by SFE in the presence of $20 \%$ ethanol as a polar co-solvent [31], while it also appeared in SFE extract of Acalypha indica without co-solvent and under different extracting conditions $\left(40^{\circ} \mathrm{C}\right.$ and $60^{\circ} \mathrm{C}, 300$ bar, $28.25 \mathrm{~g} / \mathrm{min}$ ) [33]. Nevertheless, $\mathrm{n}$-hexadecanoic acid is soluble in $\mathrm{CO}_{2}$ due to the prescence of long hydrocarbon chain that increases the non-polar characteristic of the compound. A greater percentage of n-hexadecanoic acid in SFE extract than Soxhlet extract was detected in three different Lamiaceae species [34].

Similarly, GCMS analysis conducted by Lee et al. (2016) on A. malaccensis leaf essential oil extracted using Soxhlet method with isopropanol as solvent revealed that the oil contained n-hexadecanoic acid $(76.3 \%)$, octadecatrienoic acid $(30.0 \%)$, squalene $(32.8 \%)$ and phytol (28\%) [21]. Phytol, the major bioactive compounds of ALEXA and ALEXB was reported to be a precursor of synthetic vitamin $\mathrm{E}$ and $\mathrm{K}$ [21]. Phytol was also reported to have properties of anticancer, antimicrobial and anti-inflammatory [22], [35][37]. On the other hand, n-hexadecanoic acid which was present in the three extracts and predominant in SFEX is reported to have antiandrogenic, antioxidant, antimicrobial and anti-inflammatory properties [35], [37].

Exclusively, the GCMS of SFEX showed a peak of $1 \mathrm{H}-$ Cycloprop[e]azulene, decahydro-1,1,7-trimethyl-4methylene $(0.4205 \%)$, a tricyclic sesquiterpene that was reported to have potential analgesic and anti-inflammatory effect [38]. 1H-Cycloprop[e]azulene, decahydro-1,1,7trimethyl-4-methylene (also known as Aromadenderene), is presumed to be the biomarker compound of Agarwood [39], and plays an important role in grading Agarwood quality [40]. Since temperature affects the extraction of chemical compounds, Aromadendrene, considered a volatile odoractive component [41] was probably lost during heating in Soxhlet extraction.

The presence of the phthalic acid esters is noticeable in SFEX and to a lesser extent in ALEXA, due to their comparable ability to dissolve non-polar compounds. It is worth to mention that Phthalic acid is an aromatic dicarboxylic acid with a distinguishable odor and is thought to be an adulterant in agarwood oil [42].

The relative contents expressed in the form of percentage of all compounds detected in ALEXA, ALEXB and SFEX analysed by GCMS are listed in Table 4. Meanwhile, the chromatograms of ALEXA, ALEXB and SFEX are presented in Fig. 1

(a)

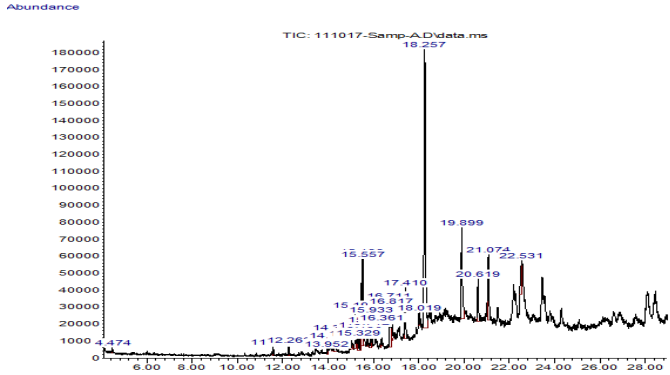

(b)

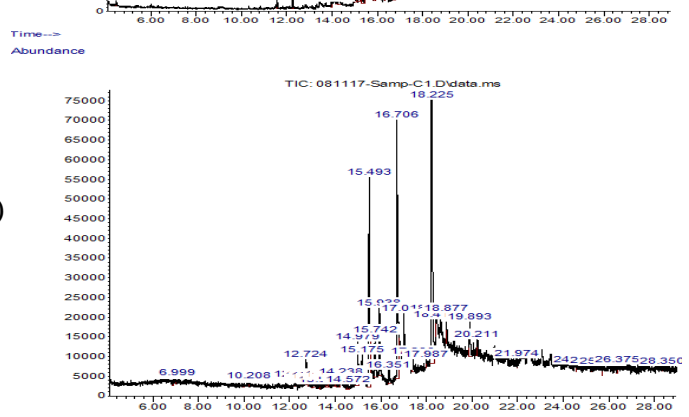

(c)

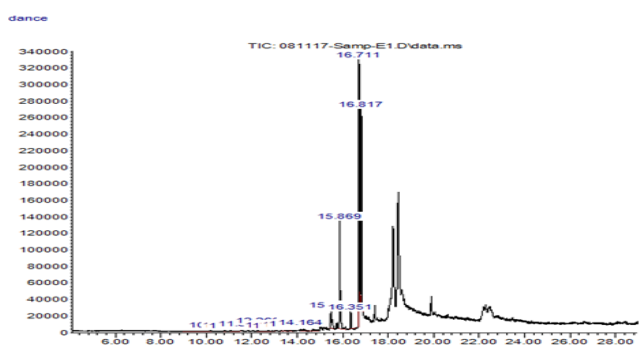

Fig. 1 GCMS Chromatogram of A.malaccensis leaf extract (a) Soxhlet; A Hexane, (b) Soxhlet; B: Ethanol and (c) Supercritical Fluid Extraction

\section{In vitro anti-inflammatory activity of Aquilaria malccensis leaf extracts}

Protein denaturation is among the manifestations associated with inflammation [43]-[45]. Consequently, agents that able to inhibit protein denaturation would be an alternative for the development of anti-inflammatory drug [5]. Hence, in-vitro study was performed as a preliminary screening to investigate the presence of anti-inflammatory activity prior to in-vivo study. 
TABLE IV

OVERALL BIOACTIVE COMPOUNDS IDENTIFIED IN ALEX; A:HEXANE AND B:ETHANOL AND SFEX: CO2 ANALYSED BY GCMS

\begin{tabular}{|c|c|c|c|c|c|}
\hline \multirow[t]{2}{*}{ No. } & \multirow[t]{2}{*}{ RT } & \multirow[t]{2}{*}{ Library/ID } & \multicolumn{2}{|c|}{ Peak Area $(\%)$} & \multirow[b]{2}{*}{ SFEX } \\
\hline & & & ALEXA & ALEXB & \\
\hline 1 & 4.47 & 1,6:3,4-Dianhydro-2-deoxy-.beta.-d-lyxo-hexopyranose & 0.388 & - & - \\
\hline 2 & 6.88 & D-erythro-Pentose, 2-deoxy- & - & 1.457 & - \\
\hline 3 & 10.00 & Cyclohexan-1,4,5-triol-3-one-1-carboxylic acid & - & 0.863 & - \\
\hline 4 & 10.20 & D-erythro-Pentose, 2-deoxy- & - & - & 1.645 \\
\hline 5 & 10.21 & Butanoic acid, 3-oxo-, propyl ester & - & 0.243 & - \\
\hline 6 & 10.82 & Acetic Acid & - & - & 0.32 \\
\hline 7 & 11.076 & Methyl N-(thioformyl)dithiocarbamate & - & - & 0.4925 \\
\hline 8 & 11.505 & Alpha,alpha,4-trimethylbenzyl carbanilate & - & - & 0.2596 \\
\hline 9 & 11.57 & 4(1H)-Pteridinone, 2-amino-6-methyl- & 0.586 & - & - \\
\hline 10 & 12.26 & 2(4H)-Benzofuranone, 5,6,7,7a-tetrahydro-4,4,7a-trimethyl- & 0.755 & - & 1.5893 \\
\hline 11 & 12.71 & D-erythro-Pentose, 2-deoxy- & - & - & 0.5692 \\
\hline 12 & 12.72 & Decane, 1-fluoro- & - & 1.470 & - \\
\hline 13 & 13.00 & Octanal & - & 0.223 & - \\
\hline 14 & 13.009 & Acetic Acid & - & - & 0.2804 \\
\hline 15 & 13.305 & $\begin{array}{l}\text { 1H-Cycloprop[e]azulene, decahydro-1,1,7-trimethyl-4- } \\
\text { methylene- }\end{array}$ & - & - & 0.4205 \\
\hline 16 & 13.31 & .alpha.-D-Mannopyranoside, methyl 3,6-anhydro- & - & 1.045 & - \\
\hline 17 & 13.480 & 1,6,10-Dodecatrien-3-ol, 3,7,11-trimethyl-,(E)- & - & - & 0.9932 \\
\hline 18 & 13.70 & Tetraacetyl-d-xylonic nitrile & - & 0.205 & - \\
\hline 19 & 13.724 & (3,7,7-Trimethyl-bicyclo[2.2.1]hept-2-yl)-methanol & - & - & 1.1163 \\
\hline 20 & 13.95 & Sulfurous acid, 2-propyl undecyl ester & 0.398 & - & - \\
\hline 21 & 13.97 & Piperidine, 3,5-dimethyl- & - & 0.332 & - \\
\hline 22 & 14.163 & 8-Dodecenol & - & - & 2.3618 \\
\hline 23 & 14.17 & Carane, 4,5-epoxy-, trans & 0.706 & - & - \\
\hline 24 & 14.17 & Cyclodecanol & - & 0.601 & - \\
\hline 25 & 14.32 & 3-Nonene & 1.572 & - & - \\
\hline 26 & 14.98 & Behenic alcohol & - & 3.802 & - \\
\hline 27 & 15.05 & Eicosane, 9-octyl- & 0.584 & - & - \\
\hline 28 & 15.18 & 5-Methyl-1,3-diazaadamantan-6-one & - & 2.910 & - \\
\hline 29 & 15.19 & 2-Propanol, 1-chloro-, phosphate (3:1) & 2.387 & - & - \\
\hline 30 & 15.27 & 5-Methyl-2-pyrazinylmethanol & 0.447 & - & - \\
\hline 31 & 15.33 & 1-Pyrazolidinethiocarboxanilide, 4-ethyl-3-propyl- & 0.858 & - & - \\
\hline 32 & 15.43 & 2-Hexadecene, 3,7,11,15-tetramethyl-, [R-[R*,R*-(E)]]- & 7.630 & - & - \\
\hline 33 & 15.49 & $\begin{array}{l}\text { Bicyclo[3.1.1]heptane, } \\
\text { (1.alpha.,2.beta.,5.alpha.)]- }\end{array} \quad$ 2,6,6-trimethyl-, $\quad$ [1R- & 6.427 & 15.966 & 5.212 \\
\hline 34 & 15.74 & 3,7,11,15-Tetramethyl-2-hexadecen-1-ol & 1.230 & - & - \\
\hline 35 & 15.74 & 1,2-Dihexylcyclopropene & - & 3.027 & - \\
\hline 36 & 15.868 & Phthalic acid, 8-chlorooctyl isobutyl ester & - & - & 17.508 \\
\hline 37 & 15.87 & Phthalic acid, butyl hexyl ester & 1.378 & - & - \\
\hline 38 & 15.93 & Bicyclo[10.8.0]eicosane, cis- & 1.999 & - & - \\
\hline 39 & 15.94 & 1,4-Eicosadiene & - & 4.417 & - \\
\hline 40 & 16.35 & 17-Octadecynoic acid, methyl ester & - & 0.893 & - \\
\hline 41 & 16.3506 & Phtalic acid, butyl cycloheptyl ester & - & - & 2.2429 \\
\hline 42 & 16.36 & Hexadecanoic acid, methyl ester & 1.594 & - & - \\
\hline 43 & 16.71 & n-Hexadecanoic acid & 4.906 & 21.449 & 38.93 \\
\hline 44 & 16.81 & Phthalic acid, butyl hexyl ester & - & - & 26.05 \\
\hline 45 & 16.82 & Phthalic acid, dodecyl ethyl ester & 2.547 & - & - \\
\hline 46 & 17.02 & Fumaric acid, 2-chloropropyl tridecyl ester & - & 3.119 & - \\
\hline 47 & 17.40 & Tetradecanal & - & 1.181 & - \\
\hline 48 & 17.41 & Isoheptadecanol & 3.788 & - & - \\
\hline 49 & 17.99 & 1,2,5-Oxadiazol-3-amine, 4-(3-methoxyphenoxy)- & - & 0.214 & - \\
\hline 50 & 18.02 & Ditetradecyl ether & 0.915 & - & - \\
\hline 51 & 18.26 & Phytol & 34.062 & 29.267 & - \\
\hline 52 & 18.42 & 10-Methyl-E-11-tridece-1-ol acetate & - & 0.510 & - \\
\hline 53 & 18.88 & Fumaric acid, 2-decyl tridecyl ester & - & 1.444 & - \\
\hline
\end{tabular}




\begin{tabular}{|c|c|c|c|c|c|}
\hline 54 & 19.89 & $\begin{array}{l}{[1,2,4] \text {-Triazolo[4,3-a][1,3,5]-triazine, 5,7-diacetylamino-3- }} \\
\text { methyl- }\end{array}$ & - & 2.892 & - \\
\hline 55 & 19.90 & cis-9-Hexadecenoic acid & 9.996 & - & - \\
\hline 56 & 20.21 & 2-(2-benzothiazolylthio)-1-(3,5- & - & 1.055 & - \\
\hline 57 & 20.62 & 4,8,12,16-Tetramethylheptadecan-4-olide & 3.953 & - & - \\
\hline 58 & 21.07 & Hexanedioic acid, bis(2-ethylhexyl) ester & 7.912 & - & - \\
\hline 59 & 21.97 & 1,1,1,3,5,5,5-Heptamethyltrisiloxane & - & 0.219 & - \\
\hline 60 & 22.53 & 13-Tetradecen-1-ol acetate & 2.983 & - & - \\
\hline 61 & 24.59 & Silicic acid, diethyl bis(trimethylsilyl) ester & - & 0.233 & - \\
\hline 62 & 25.27 & $\begin{array}{l}\text { 1-Nitro-9,10-dioxo-9,10-dihydro-anthracene-2-carboxylic } \\
\text { acid diethylamide }\end{array}$ & - & 0.219 & - \\
\hline 63 & 25.70 & 9-Borabicyclo[3.3.1]nonane, 9-[3-(dimethylamino)propyl]- & - & 0.261 & - \\
\hline 64 & 26.37 & (5-Isopropyl-2-methylphenoxy)trimethylsilane & - & 0.275 & - \\
\hline 65 & 28.35 & 1,4-Bis(trimethylsilyl)benzene & - & 0.211 & - \\
\hline
\end{tabular}

The in-vitro study showed that the extracts demonstrated inhibition of protein (albumin) denaturation in a concentration-dependent manner throughout a concentration range of $400-16000 \mu \mathrm{g} / \mathrm{ml}$ as depicted in Fig. 2. The three extracts showed similar trend of inhibition with ALEXB showing higher percentage of inhibition $(70.045 \pm 7.22)$ at concentration $16000 \mu \mathrm{g} / \mathrm{ml}$ as compared to ALEXA and SFEX. In the meantime, it can be seen in Fig. 2 that the extracts gave almost $50 \%$ inhibition of protein denaturation around $8000 \mu \mathrm{g} / \mathrm{ml}$. The findings are consistent with another study where crude ethanolic extract of $A$. agallocha leaves was reported to inhibit Bovine Serum Albumin (BSA) denaturation $(34.09 \%, 36.95 \%$ and $43.13 \%)$ at different concentrations $(100,250$ and $500 \mu \mathrm{g} / \mathrm{ml})$ of the extract [46].

In more detail, phytol; an acyclic diterpene alcohol (the major compound of ALEXA and ALEXB) identified by GCMS analsysis has been reported for being able to reduce neutrophil migration, cytokine levels and oxidative stress in acute inflammation models [36]. Maruthupandian and Mohan (2011) stated that phytol was detected in Sneeze wort (Wattakaka volubilis) ethanolic leaf extract constitute a promising novel therapeutic agent for rheumoid arthritis and other related chronic inflammatory diseases [37]. Meanwhile, n-hexadecanoic acid, which was found to be the major compound of SFEX (38.93\%) and also found to a lesser extent in ALEXA (4.2\%) and ALEXB (21.5\%), was indicated to have potential anti-inflammatory and antiarthritic properties [37]. Aparna et al., (2012) reported that hexadecanoic acid controls inflammation through inhibition of phospholipase A2 enzyme by binding to its active site [47]. In addition, 1H-Cycloprop[e]azulene, decahydro-1,1,7trimethyl-4-methylene, is a tricyclic sesquiterpene that was found solely in SFEX and

was previously testified to have potential analgesic and antiinflammatory activity [38]. Therefore, the anti-inflammatory activity of ALEX may be attributed to the presence of phytol and n-hexadecanoic acid, while the anti-inflammatory activity of SFEX may be due to the occurrence of nhexadecanoic acid and 1H-Cycloprop[e]azulene, a biomarker and a chemical distinguisher of Agarwood [39].

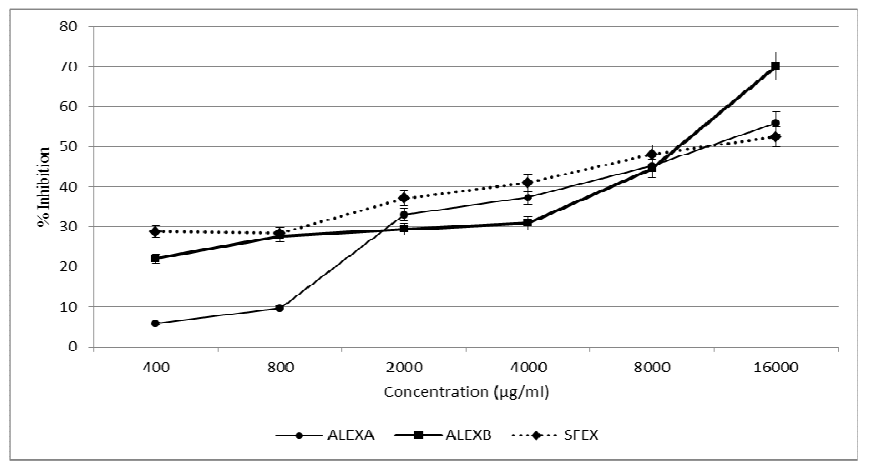

Fig. 2 Anti-inflammatory activity of Aquilaria malaccensis leaf extracts. Percentage of protein denaturation inhibition against concentration range of 400-16 $000 \mu \mathrm{g} / \mathrm{ml}$. Experiments were conducted in triplicates.

\section{CONCLUSION}

In conclusion, the present study revealed the antiinflammatory properties of Aquilaria malaccensis leaf extracted using Soxhlet with polar and non-polar solvents, and Supercritical Fluid Extraction respectively. The extracts were able to inhibit more than $50 \%$ of the heat-induced protein denaturation with ethanolic Soxhlet extract (ALEXB) showing the highest anti- inflammatory activity. Further research is warranted to explore the anti-inflammatory activities of $A$. malaccensis leaf extracts and their mechanism of action.

\section{ACKNOWLEDGEMENT}

The authors would like to acknowledge the International Islamic University Malaysia (IIUM) for the Research Initiative Grant Scheme (RIGS17-145-0720) received in support for this present study.

\section{REFERENCES}

[1] R. Fürst, and I. Zündorf, "Plant-derived anti-inflammatory compounds: Hopes and disappointments regarding the translation of preclinical knowledge into clinical progress," Mediators of $\begin{array}{lllll}\text { Inflammation, vol. } 2014, \quad \text { pp. } & 1-9, & 2014 .\end{array}$ https://doi.org/10.1155/2014/146832

[2] H. Rahman, K. Vakati, and M. C Eswaraiah, "In-vivo and in-vitro anti-inflammatory activity of Aquilaria agallocha oil," International Journal of Basic Medical Sciences and Pharmacy (IJBMSP), vol. 2, pp. 7-10, 2012. 
[3] J. S. Davis, H. Y. Lee, J. Kim, S. M. Advani, H. L. Peng, E. Banfield, E. T. Hawk, and A. C. Frazier-Wood, "Use of non-steroidal antiinflammatory drugs in US adults: changes over time and by demographic," Open heart, vol. 4, e000550, 2017.

[4] T. Chitre, P. Bhutada, K. Nandakumar, R. Somani, P. Miniyar, Y. Mundhada, S. Gore, and K. Jain, "Analgesic and anti-inflammatory activity of heartwood of Aquilaria agallocha in laboratory animals," Pharmacol Online, vol. 1, pp.288-298, 2007.

[5] S. Banerjee, A. Chanda, A. Adhikari, A. K. Das, and S. Biswas, "Evaluation of phytochemical screening and anti inflammatory activity of leaves and stem of Mikania scandens (1.) wild," Annals of Medical and Health Sciences Research, vol. 4, pp.532-536, 2014.

[6] NF. Shafiee, MSA. Karim, AB. Razali. and UF. Zainal Abidin, "Halalan Toiyyiban Food Handling Practices: A Review on Street Food Vendors in Malaysia," Journal of Islamic, Social, Economics and Development (JISED), vol. 2, pp. 385-394, 2017.

[7] F. Mohammadian, and B. Hajipour, "Halal cosmetics supply chain-a conceptual model," International Journal of Supply Chain Management, vol. 5, pp.33-43, 2016.

[8] H. Zhao, Q. Peng, Z. Han, L. Yang, and Z. Wang, "Three new sesquiterpenoids and one new sesquiterpenoid derivative from Chinese eaglewood," Molecules, vol. 21, pp. 5-12, 2016. https://doi.org/10.3390/molecules21030281

[9] H. Yuan, J. Zhao, M. Wang, S.I. Khan, C. Zhai, Q. Xu, and I.. A. Khan, "Benzophenone glycosides from the flower buds of Aquilaria sinensis," Fitoterapia, vol. 121, pp. 170-174, 2017. https://doi.org/10.1016/j.fitote.2017.07.013

[10] H. X. Huo, Z. X. Zhu, Y. L. Song, S. P. Shi, J. Sun,... and P. F. Tu, "Anti-inflammatory dimeric 2-(2-phenylethyl) chromones from the resinous wood of Aquilaria sinensis," Journal of Natura $\begin{array}{llll}\text { Products, vol. } & \text { 81, } & \text { pp. } & \text { 543-553, }\end{array}$ https://doi.org/10.1021/acs.jnatprod.7b00919

[11] V. D. Wagh, M. Korinek, I. W. Lo, Y. M. Hsu, S.L. Chen, H. Y. Hsu,... and F. R. Chang, "Inflammation Modulatory Phorbol Ester from the Seeds of Aquilaria malaccensis," Journal of Natural Products, vol. 80, pp. 1421-1427, 2017. https://doi.org/10.1021/acs.jnatprod.6b01096

[12] W. Thitikornpong, B. Ongpipattanakul, C. Palanuvej, and N. Ruangrungsi, "Pharmacognostic specification and mangiferin content of Aquilaria crassna leaves", Pharmacog Journal, Vol. 10, 2017.

[13] K. Hamid, and K. Halim, (n.d.), Enhancing the world of fragrance through Malaysian Bio-Gaharu, Professional Lecture, presented at UPENA, Shah Alam, ISBN 978-967-363-199-5, 2011

[14] CITES. (2011) Convention on international trade in endangered species of wild fauna and flora appendices I, II and III [Online]. Available: http://www.cites.org/eng/app/appendices.php

[15] A. Z. Adam, S. Y. Lee, and R. Mohamed, "Pharmacological properties of agarwood tea derived from Aquilaria (Thymelaeaceae) leaves: An emerging contemporary herbal drink," Journal of Herbal Medicine, vol. 10, pp. 37-44, 2017.

[16] A.M. Rashid and Y. A. Zuhaidi, Tapping the wealth from Karas (Aquilaria malaccensis) tree, ser. Malayan Forest Records. Selangor, Malaysia: Reka Cetak Sdn Bhd, 2011, pp.8-15.

[17] Y. Z. H.- Y. Hashim, P. G. Kerr, P. Abbas, and H. M. Salleh, "Aquilaria spp. (agarwood) as source of health beneficial compounds: A review of traditional use, phytochemistry and pharmacology," Journal of Ethnopharmacology vol. 189, pp.331-360, 2016.

[18] A. S. Khalil, A. A. Rahim, K. K. Taha, and K. B. Abdallah, "Characterization of methanolic extracts of agarwood leaves," Journal of Applied and Industrial Sciences, vol. 1, pp.78-88, 2013.

[19] A. Ibrahim "Comparative analysis of in vitro bioactivities and phenolic content of leaf extracts from six species of Aquilaria", doctoral dissertation, Universiti Sains Malaysia, 2016

[20] A. Ahmad, "Optimization of soxhlet extraction of Herba Leonuri using factorial design of experiment," International Journal of Chemistry, vol. $\quad 2, \quad$ pp. $\quad 198-205, \quad 2010$. https://doi.org/10.5539/ijc.v2n1p198.

[21] N. Y. Lee, M. A. C .Yunus, Z. Idham, M. S. H. Ruslan, A. H. A Aziz, and N. Irwansyah, "Extraction and identification of bioactive compounds from agarwood leaves" in IOP Conference Series: Materials Science and Engineering, 2016, vol. 162, No. 1, p. 012028.

[22] F. P. Casuga, A. L. Castillo, and M. J. A. T. Corpuz, GC-MS analysis of bioactive compounds present in different extracts of an endemic plant Broussonetia luzonica (Blanco) (Moraceae) leaves,"
Asian Pacific Journal of Tropical Biomedicine, vol. 6, pp. 957-961, 2016.

[23] Y. Z. H. -Y. Hashim, N. I. Ismail, and P. Abbas, "Analysis of chemical compounds of agarwood oil from different species by gas chromatography mass spectrometry (GCMS)," IIUM Engineering Journal, vol. 15, pp. 55-60, 2014.

[24] H. Hendra, S. Moeljopawiro, and T.R. Nuringtyas, "Antioxidant and antibacterial activities of agarwood (Aquilaria malaccensis Lamk.) leaves," in AIP Conference Proceedings (Vol. 1755, No. 1, p. 140004), 2016.

[25] M. Bimakr, R. A. Rahman, F. S. Taip, A. Ganjloo, L. M. Salleh, J. Selamat, A. Hamid, and I. S. M. Zaidul, "Comparison of different extraction methods for the extraction of major bioactive flavonoid compounds from spearmint (Mentha spicata L.) leaves," Food and Bioproducts Processing, vol. 89, pp. 67-72, 2011.

[26] L. Muruganandam, A. Krishna, J. Reddy, and G. S. Nirmala, "Optimization studies on extraction of phytocomponents from betel leaves," Resource-Efficient Technologies, vol. 3, pp.385-393, 2017.

[27] K. Kőszegi, G. Vatai, and E. Békássy-Molnár, "Comparison the soxhlet and supercritical fluid extraction of nettle root (Urtica dioica L.), " Periodica Polytechnica Chemical Engineering, vol. 59, pp. 168173, 2015.

[28] N. R. Putra, M. A. C.Yunus, M. S. H.Ruslan, Z. Idham, and F. N. Idrus, "Comparison extraction of peanut skin between $\mathrm{CO} 2$ supercritical fluid extraction and soxhlet extraction in term of oil yield and catechin”, Pertanika Journal of Science \& Technology, vol. 26, pp. 799-810, 2018.

[29] M.N. Hasmida, M.S. Liza, A.R. Nur Syukriah, Y. Harisun, C.Y. Mohd Azizi, and A.M. Fadzilah Adibah, "Total phenolic content and antioxidant activity of Quercus infectoria galls using supercritical $\mathrm{CO} 2$ extraction technique and its comparison with soxhlet extraction," Pertanika Journal of Science \& Technology, vol. 23, pp. 287-295, 2015

[30] P. Wetwitayaklung, N. Thavanapong, and J. Charoenteeraboon, "Chemical constituents and antimicrobial activity of essential oil and extracts of heartwood of Aquilaria crassna obtained from water distillation and supercritical fluid carbon dioxide extraction," Silpakorn U Science \& Technology Journal, vol. 3, pp. 25-33, 2009.

[31] S. Al-Hamimi, A. Abellan Mayoral, L. P. Cunico, and C. Turner, "Carbon dioxide expanded ethanol extraction: Solubility and extraction kinetics of $\alpha$-pinene and cis-verbenol," Analytical chemistry, vol. 88, pp.4336-4345, 2016.

[32] P. P. Almeida, N. Mezzomo, and S. R. Ferreira, "Extraction of Mentha spicata L. volatile compounds: evaluation of process parameters and extract composition," Food and Bioprocess Technology, vol. 5, pp. 548-559, 2012

[33] S. Chaichoowonga, J. B. Bolb, P. Bolc, T. Gamseb, and M Sriariyanuna, "Chemical Profiling of Acalypha Indica Obtained from Supercritical Carbon Dioxide Extraction and Soxhlet Extraction Methods," Oriental Journal of Chemistry, vol. 33, pp. 66-73, 2017.

[34] R. Rodríguez-Solana, J. M. Salgado, J. M. Domínguez, and S. Cortés-Diéguez, "Comparison of soxhlet, accelerated solvent and supercritical fluid extraction techniques for volatile (GC-MS and GC/FID) and phenolic compounds (HPLC-ESI/MS/MS) from Lamiaceae Species," Phytochemical analysis, vol. 26, pp. 61-71, 2015 .

[35] M. Sermakkani, and V. Thangapandian, "GC-MS analysis of Cassia italica leaf methanol extract," Asian Journal of Pharmaceutical and Clinical Research, vol. 5, pp. 90-94, 2012.

[36] R. O. Silva, F. B. M. Sousa, S. R. Damasceno, N. S. Carvalho, V. G. Silva, F. R. Oliveira, D. P. Sousa, K. S. Aragão, A. L. Barbosa, R. M. Freitas, and J. V. R. Medeiros, "Phytol, a diterpene alcohol, inhibits the inflammatory response by reducing cytokine production and oxidative stress," Fundamental \& Clinical Pharmacology, vol. 28, pp. 455-464, 2014.

[37] A. Maruthupandian, and V. R. Mohan, "GC-MS analysis of ethanol extract of Wattakaka volubilis (lf) stapf. Leaf," International Journal of Phytomedicine, vol. 3, pp. 59, 2011.

[38] M.J. Chavan, P.S. Wakte, and D.B. Shinde, "Analgesic and antiinflammatory activities of the sesquiterpene fraction from Annona reticulata L. bark," Natural Product Research, vol. 26, pp. 1515-1518, 2012.

[39] G. Pasaribu, T. K. Waluyo, and G. Pari, "Analysis of chemical compounds distinguisher for agarwood qualities," Indonesian Journal of Forestry Research, vol. 2, pp. 1-7, 2015 
[40] K. Jayachandran, I. Sekar, K. T. Parthiban, D. Amirtham, and K. K. Suresh, " Analysis of different grades of agarwood (Aquilaria malaccensis Lamk.) oil through GC-MS," Indian Journal of Natural Products and Resources (IJNPR)[Formerly Natural Product Radiance (NPR)], vol. 5, pp. 44-47, 2015

[41] N. Ismail, N. A. M. Ali, M. Jamil, M. H. F. Rahiman, M. N. Taib, and S. N. Tajuddin, "Major Volatile Chemical Compounds of Agarwood Oils from Malaysia Based on Z-Score Technique," Chemistry of Natural Compounds, vol. 51, pp. 776-779, 2015.

[42] (2016) Ouddict website. [Online]. Available: http://www.ouddict.com/threads/oud-oil-and-wood-adulteration.129/

[43] S. Chandra, P. Chatterjee, P. Dey, and S. Bhattacharya, "Evaluation of in vitro anti-inflammatory activity of coffee against the denaturation of protein," Asian Pacific Journal of Tropical Biomedicine, vol. 2, pp. 2011-2013, 2012. https://doi.org/10.1016/S2221-1691(12)60154-3
[44] M. Anoop, and A. Bindu, "In-vitro anti-inflammatory activity studies on Syzygium zeylanicum (L.) DC leaves," International Journal of Pharma Research \& Review, vol. 4, pp. 18-27, 2015.

[45] K. Karthik, P. B. R. Kumar, R. Venu Priya, K, R. S. B. R. Sunil Kumar, "Evaluation of anti-inflammatory activity of Canthium parviflorum by in-vitro method," Indian Journal of Research in Pharmacy and Biotechnology, vol. 1, pp. 729-731, 2013.

[46] H. Rahman, M.C. Eswaraiah, and A.M. Dutta, "Anti-arthritic activity of leaves and oil of Aquilaria agallocha", The Saudi Journal of Life Sciences, vol. 1, pp. 34-43, 2016.

[47] V. Aparna, K.V. Dileep, P.K. Mandal, P. Karthe, C. Sadasivan, and M. Haridas, "Anti-inflammatory property of n-hexadecanoic acid: structural evidence and kinetic assessment," Chemical Biology and Drug Design, vol. 80, pp. 434-439, 2012. https://doi.org/10.1111/j.1747-0285.2012.01418.x 